\title{
03.5
}

\section{Карта режимов течения вода-нефть в прямом микроканале}

\author{
() М.И. Пряжников ${ }^{1,2}$, А.В. Минаков ${ }^{1,2}$, А.И. Пряжников ${ }^{1}$, А.С. Якимов ${ }^{1}$ \\ ${ }^{1}$ Сибирский фредеральный университет, Красноярск, Россия \\ ${ }^{2}$ Институт теплофизики им. С.С. Кутателадзе СО РАН, Новосибирск, Россия \\ E-mail: mpryazhnikov@sfu-kras.ru
}

Поступило в Редакцию 21 сентября 2021 г.

В окончательной редакции 13 октября 2021 г.

Принято к публикации 15 октября 2021 г.

\begin{abstract}
Изучены режимы течения воды и сырой нефти в микроканале $Y$-типа в широком диапазоне расходов. Выявлены четыре различных типа режимов течения вода-нефть: снарядный, капельный, параллельный и хаотический. Определены диапазоны существования этих режимов течения. Установлены зависимости длины снарядов и капель воды в нефти от различных параметров. Построены карты соответствующих режимов течения вода-нефть.
\end{abstract}

Ключевые слова: $Y$-микроканал, течение жидкость-жидкость, несмешивающиеся жидкости, карта режимов течения.

DOI: 10.21883/PJTF.2022.03.51973.19030

Течения несмешивающихся жидкостей имеют широкое распространение в природе и технике. Особенную важность исследование режимов течения несмешивающихся жидкостей имеет в задачах вытеснения нефти при заводнении пласта. Известно, что многие методы увеличения нефтеотдачи основаны на управлении режимами течения нефти и вытесняющих жидкостей. Увеличение нефтеотдачи из микропористой среды зависит от структуры течения в поровом пространстве. В свою очередь структура потока, возникающая в микропористой среде, зависит от нескольких параметров: геометрии (характерного размера и типа соединений микроканалов пористой среды), физических свойств нефти и вытесняющей жидкости для улучшения нефтеотдачи.

Несмотря на сравнительно большое число работ $[1,2]$, посвященных изучению течений нефти в микропористых средах, систематических данных об имеющихся режимах течения в них все еще недостаточно. Число факторов, влияющих на режимы течения при нефтеотдаче, столь велико, что необходимо их дальнейшее изучение. В связи с этим целью настоящей работы является систематическое изучение режимов течений воды и нефти в прямом микроканале, имитирующем пору. Для этих целей использовалась микрофлюидная технология, которая в последнее время широко применяется для изучения течений при вытеснении нефти из пористой среды $[3,4]$.

Исследование проведено на микрофлюидном чипе с микроканалом $Y$-типа (рис. $1, a)$. Чип был изготовлен из полиметилметакрилата методом фрезерования и термоспекания. Ширина $w$ и высота $h$ микроканала составляли 500 и $200 \mu \mathrm{m}$, длина $-20 \mathrm{~mm}$, длина и ширина входных участков - $5 \mathrm{~mm}$ и $250 \mu \mathrm{m}$ (см. схему на рис. $1, b)$. В работе использовались дистиллированная вода и легкая маловязкая нефть $\left(825 \pm 3 \mathrm{~kg} \cdot \mathrm{s}^{-1}, 8.5 \pm 0.2 \mathrm{mPa} \cdot \mathrm{s}\right)$. Межфазное натяжение, измеренное тензиометром, на границе вода-нефть составляло $22.5 \pm 0.1 \mathrm{mN} \cdot \mathrm{m}^{-1}[5]$. Равновесное значение краевого угла смачивания было равно $124 \pm 2^{\circ}$. Нефть и вода закачивались в микрофлюидный чип с помощью шприцевых насосов, позволяющих задавать расход с относительной погрешностью $0.5 \%$. Микроканал располагался горизонтально на предметном столике микроскопа. Входы микроканала соединялись со шприцами (Hamilton) трубками из полипропилена с внутренним диаметром $1.2 \mathrm{~mm}$. Задавался объемный расход жидкостей $Q$. Картина течения жидкостей фиксировалась высокоскоростной камерой. Для описания режимов течения использовались традиционные параметры. Число Рейнольдса отвечает за отношение сил инерции к вязкостным силам: $\operatorname{Re}=\frac{\rho U D}{\mu}$, где $\rho-$ плотность жидкости, $U-$ характерная скорость, $D$ - гидравлический диаметр канала, равный $286 \mu \mathrm{m}, \mu$ - динамическая вязкость жидкости. Число Вебера характеризует баланс между силами инерции и поверхностного натяжения: $\mathrm{We}=\frac{\rho U^{2} D}{\sigma}, \sigma-$ поверхностное натяжение. Капиллярное число устанавливает отношение между силами вязкости и поверхностного натяжения: $\mathrm{Ca}=\frac{\mu U}{\sigma}$. Еще одним критерием подобия является число Онезорге, равное отношению вязкостных сил к силам поверхностного натяжения: $\mathrm{Oh}=\frac{\mu}{\sqrt{\rho \sigma D}}$. Эксперименты проводились в широком диапазоне расходов жидкостей и чисел подобия. Диапазоны критериев подобия представлены в таблице.

В результате исследования были установлены четыpe различных типа режимов течения вода-нефть в $Y$-микроканале: снарядный, капельный, параллельный и хаотический. Типичные изображения этих режимов показаны на рис. 2. Снарядный режим течения наблюдается при малых расходах воды и нефти. Во всех экспериментах в этом режиме формируются снаряды воды. Нефть является несущей средой, так как она лучше 


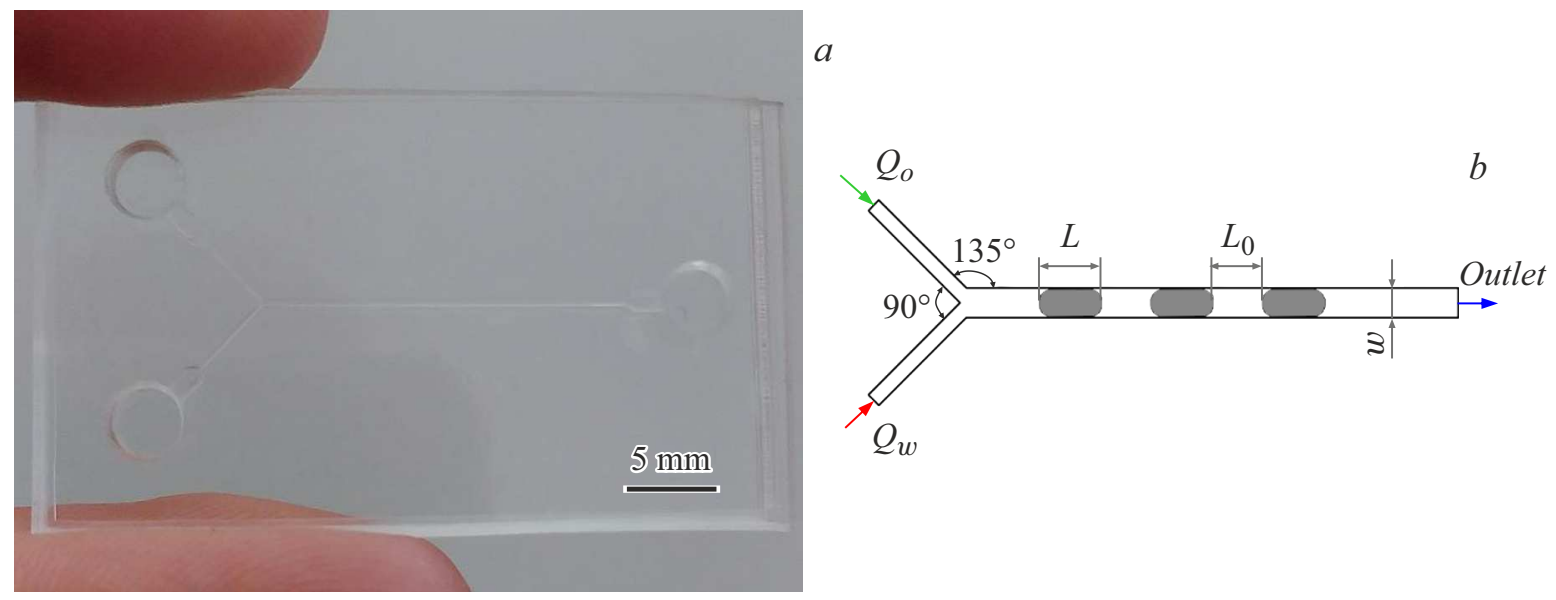

Рис. 1. Фотография микрофлюидного чипа с микроканалом $Y$-типа $(a)$ и его схема $(b)$.

Диапазоны экспериментальных параметров

\begin{tabular}{c|c|c}
\hline Параметр & Вода & Сырая нефть \\
\hline$Q, \mathrm{ml} / \mathrm{h}$ & $2.5 \cdot 10^{-2}<Q_{w}<6.6 \cdot 10^{2}$ & $10^{-1}<Q_{o}<55$ \\
$\mathrm{Re}$ & $2.2 \cdot 10^{-2}<\mathrm{Re}_{w}<5.8 \cdot 10^{2}$ & $7.7 \cdot 10^{-3}<\mathrm{Re}_{o}<4.2$ \\
$\mathrm{We}$ & $6.1 \cdot 10^{-8}<\mathrm{We}_{w}<43$ & $9.5 \cdot 10^{-8}<\mathrm{We}_{o}<2.8 \cdot 10^{-2}$ \\
$\mathrm{Oh}$ & $1.12 \cdot 10^{-2}$ & $1.17 \cdot 10^{-1}$ \\
$\mathrm{Ca}$ & $2.8 \cdot 10^{-6}<\mathrm{Ca}_{w}<7.3 \cdot 10^{-2}$ & $1.1 \cdot 10^{-4}<\mathrm{Ca}_{o}<5.7 \cdot 10^{-2}$
\end{tabular}
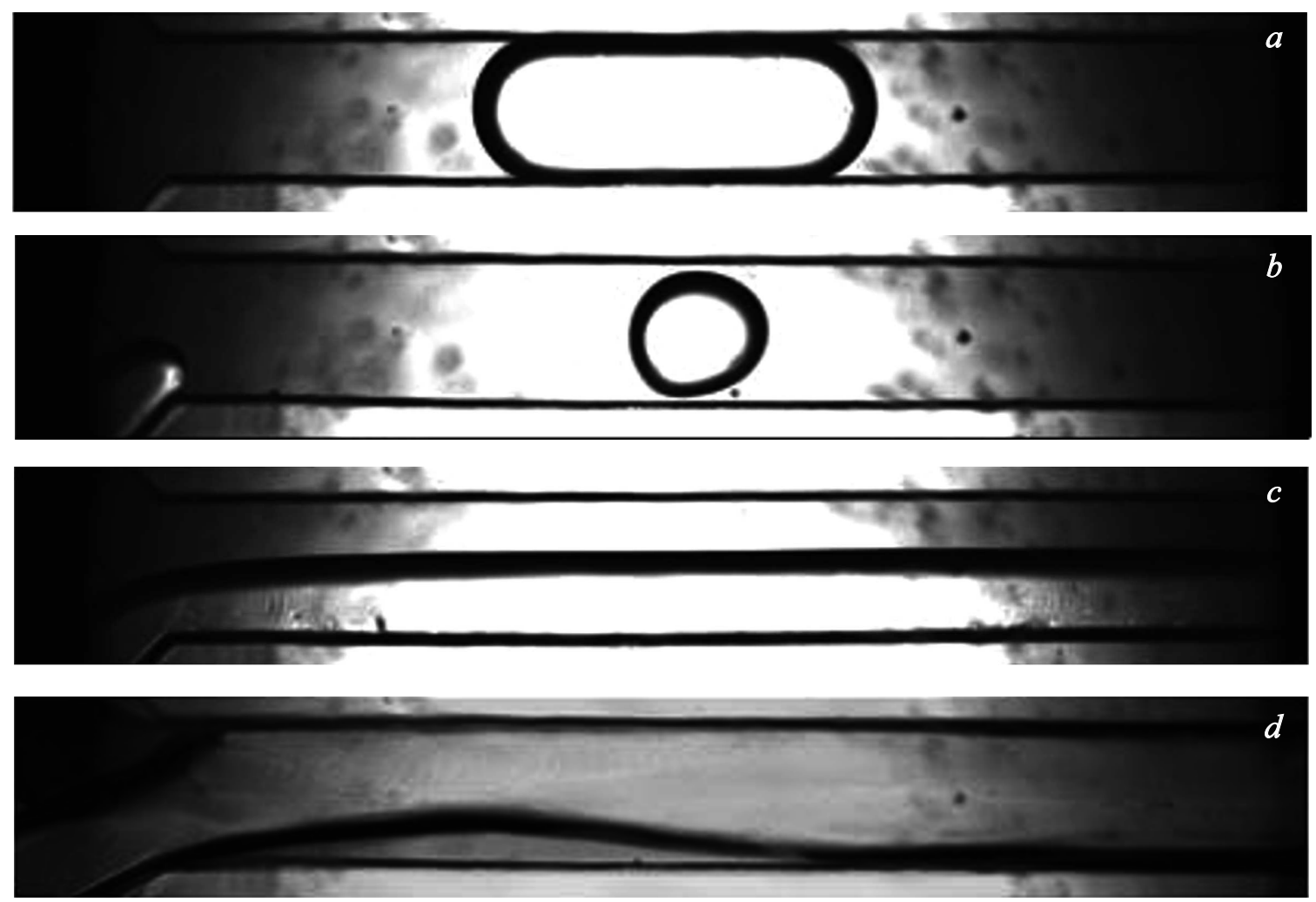

Рис. 2. Наблюдаемые режимы течения: $a-$ снарядный, $b-$ капельный, $c-$ параллельный, $d-$ хаотический. 

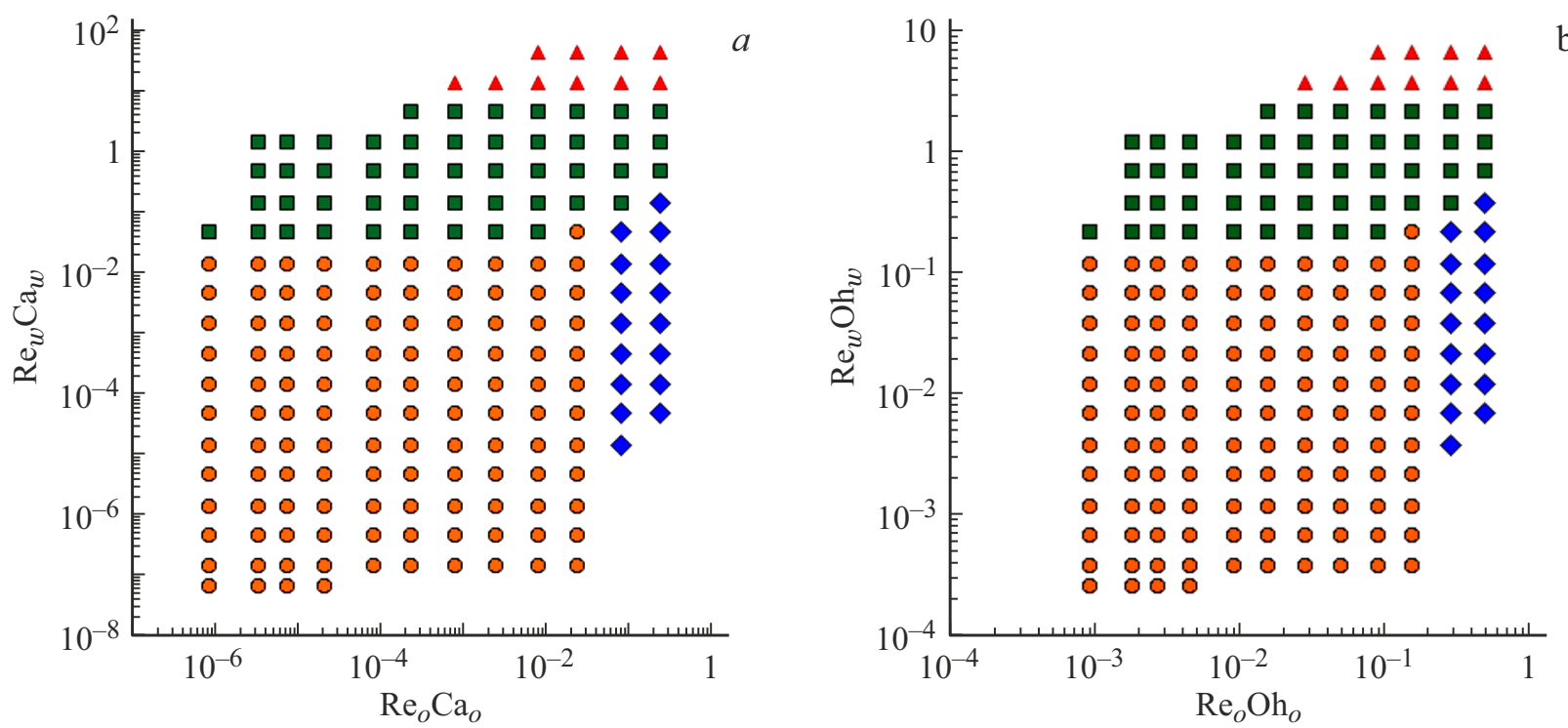

b

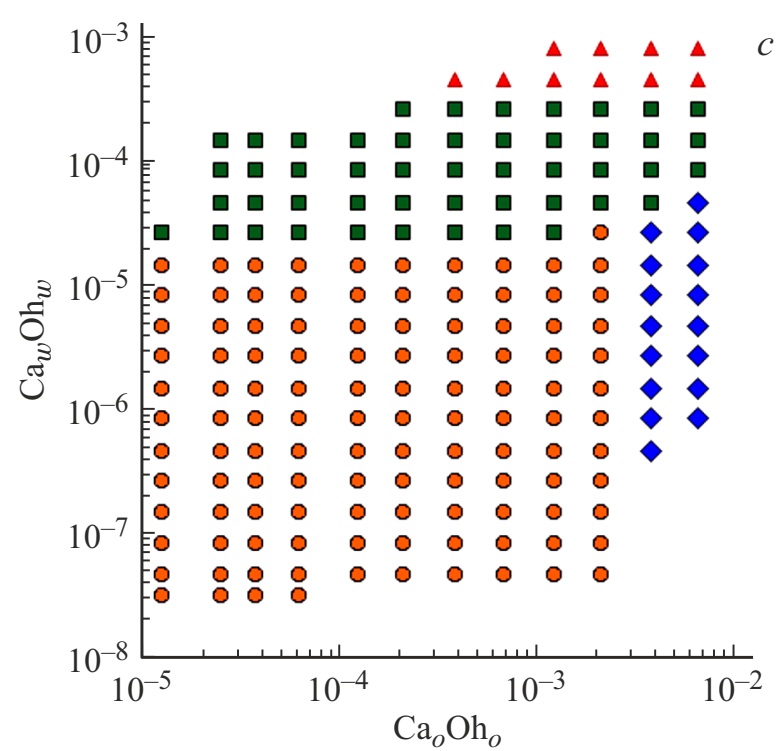

Рис. 3. Карта режимов течения вода-нефть в координатах комбинированных чисел $\mathrm{ReCa}(a), \operatorname{ReOh}(b)$ и $\mathrm{CaOh}(c)$. Kвадрат параллельный режим, кружок - снарядный режим, ромб - капельный режим, треугольник - хаотический режим.

смачивает стенки канала. Вода выступает в качестве дисперсной фазы. Разделение дисперсной фазы на снаряды определяется межфазным натяжением. Снаряд воды занимает почти все поперечное сечение микроканала с очень тонкой пленкой нефти между снарядом воды и стенкой микроканала. При постоянном расходе воды (дисперсной фазы) наблюдалось уменьшение длины снаряда при увеличении расхода нефти. Такая же тенденция имела место при постоянном расходе нефти, но при уменьшении расхода воды.

В результате анализа экспериментальных данных была получена следующая корреляция, описывающая длину снарядов $L$ :

$$
\frac{L}{D}=\varepsilon+k\left(\frac{Q_{d}}{Q_{c}}\right)^{\alpha}\left(\frac{1}{\mathrm{Ca}_{c}}\right)^{\beta},
$$

где $\varepsilon=1.72, k=1.45, \alpha=0.525, \beta=0.138$ - параметры корреляции, определенные методом наименьших квадратов; индекс $d$ соответствует дисперсной фазе, индекс $c$ - несущей фазе.

Дальнейшее увеличение расхода нефти приводило к переходу в капельный режим течения. В этом режиме размер капель воды меньше размера микроканала (рис. $2, b$ ). Он реализуется при высоких расходах нефти и низких расходах воды. Дробление воды на капли связано с большим влиянием сил инерции, которые возникают при высоких расходах нефти. Для капельного режима, так же как и для снарядного режима течения, безразмерная длина капель хорошо описывается корреляцией (1). Параметры корреляции (1) для капельного режима течения следующие: $\varepsilon=1.17, k=0.0926$, $\alpha=0.412, \beta=0.936$. 
При более высоких расходах воды и нефти сила инерции преобладает над силой межфазного натяжения, и жидкости текут параллельно друг другу без образования снарядов или капель. Реализуется так называемый параллельный режим течения, представленный на рис. 2,c. Эксперименты показывают, что положение границы раздела между нефтью и водой внутри микроканала смещается по мере изменения расходов воды и нефти.

При дальнейшем увеличении расхода воды происходит переход от параллельного режима течения к хаотическому (рис. $2, d$ ), который реализуется при очень высоких расходах воды и нефти. При больших скоростях нефти и воды в результате действия центробежных сил формируется неодномерное течение. В этом режиме потоки воды и нефти переворачиваются в канале смешения, а затем текут в параллельном режиме вдоль противоположных стенок. Аналогичное поведение наблюдалось при однофазном течении жидкости в микроканале $T$-типа. Систематические исследования однофазного течения в $T$-микроканале при высоких числах Рейнольдса можно найти в [6]. В результате развития вторичного течения Дина образуется пара симметричных подковообразных вихрей, которые затухают в микроканале, причем каждый из этих вихрей находится внутри одной и той же жидкости (вода или нефть). Начиная с числа Рейнольдса, равного примерно 145, пара подковообразных вихрей разворачивается под углом $30^{\circ}$ к центральной продольной плоскости микроканала, что приводит к затуханию одного из вихрей и усилению другого. Подобная ситуация наблюдается и в данном случае. Потоки нефти и воды в канале смешения также переворачиваются.

В работе проведено экспериментальное исследование течения вода-нефть в микроканале $Y$-типа. Получена карта режимов течения жидкостей. Установлено четыре различных типа режимов течения: параллельный, капельный, снарядный и хаотический. Построена карта режимов течения вода-нефть в координатах комбинированных чисел Рейнольдса, Онезорге и капиллярного числа (рис. 3). В настоящий момент нет единого мнения о том, относительно каких параметров следует строить карты режимов течений для двухфазных потоков в микроканалах. Во многих (обычно более ранних) работах для характеризации режимов течения использовались скорости или расходы фаз [7,8]. Также распространено использование для классификации режимов числа Рейнольдса [8]. В работе [9] карта режимов течения построена относительно числа Вебера. Часто для описания режимов течения используются комбинации чисел в различных степенях. В настоящей работе для описания режимов течения воспользуемся комбинированными числами: Рейнольдса и капиллярного числа (рис. 3,a), Рейнольдса и Онезорге (рис. $3, b)$, капиллярного числа и числа Онезорге (рис. 3,c). Эти параметры наиболее удобны для использования в задачах увеличения нефтеотдачи.
Таким образом, с помощью микрофлюидного эксперимента изучены режимы течения вода-нефть в прямом микроканале, имитирующем пору. Определены диапазоны существования этих режимов течения. Установлены зависимости длины снарядов и капель воды в нефти от соотношения расходов воды и нефти, а также от капиллярного числа, рассчитанного по несущей фазе. Построены карты соответствующих режимов течения вода-нефть. Эти данные будут полезны при разработке методов увеличения нефтеотдачи.

\section{Благодарности}

Авторы выражают благодарность Красноярскому региональному центру коллективного пользования (Красноярский научный центр Сибирского отделения Российской академии наук).

\section{Финансирование работы}

Исследование проведено в рамках государственного задания Сибирскому федеральному университету (номер FSRZ-2020-0012).

\section{Конфликт интересов}

Авторы заявляют, что у них нет конфликта интересов.

\section{Список литературы}

[1] A. Perazzo, G. Tomaiuolo, V. Preziosi, S. Guido, Adv. Coll. Interface Sci., 256, 305 (2018). DOI: 10.1016/j.cis.2018.03.002

[2] J. Foroozesh, S. Kumar, J. Mol. Liq., 316, 113876 (2020). DOI: $10.1016 /$ j.molliq.2020.113876

[3] M. Saadat, J. Yang, M. Dudek, G. Øye, P.A. Tsai, J. Pet. Sci. Eng., 203, 108647 (2021). DOI: 10.1016/j.petrol.2021.108647

[4] X. Zhao, Y. Feng, G. Liao, W. Liu, J Coll. Interface Sci., 578, 629 (2020). DOI: 10.1016/j.jcis.2020.06.019

[5] А.В. Минаков, М.И. Пряжников, Я.Н. Сулемана, В.Д. Мешкова, Письма в ЖТФ, 46 (24), 30 (2020). DOI: 10.21883/PJTF.2020.24.50425.18520 [A.V. Minakov, M.I. Pryazhnikov, Y.N. Suleymana, V.D. Meshkova, Tech. Phys. Lett., 46 (12), 1238 (2020). DOI: $10.1134 / \mathrm{S} 1063785020120238]$.

[6] A.S. Lobasov, A.V. Minakov, Chem. Eng. Process. - Process Intensif., 124, 11 (2018). DOI: 10.1016/j.cep.2017.11.004

[7] I. Mudawar, J. Electron. Packag. Trans. ASME, 133 (4), 041002 (2011). DOI: $10.1115 / 1.4005300$

[8] H. Foroughi, M. Kawaji, Int. J. Multiphase Flow., 37 (9), 1147 (2011). DOI: 10.1016/j.ijmultiphaseflow.2011.06.004

[9] Y. Zhao, G. Chen, Q. Yuan, AIChE J., 52 (12), 4052 (2006). DOI: 10.1002/aic.11029 